\title{
POTENTIALITIES AND LIMITS OF ICESAT-2 OBSERVATION FOR ATMOSPHERIC AEROSOL INVESTIGATION
}

\author{
L. Mona ${ }^{1 *}$, A. Amodeo' ${ }^{1}$ G. D'Amico' \\ ${ }^{1}$ Istituto di Metodologie per l'Analisi Ambientale CNR-IMAA, C.da S. Loja, I-85050 Tito Scalo, Potenza, \\ Italy,*Email: lucia.mona@imaa.cnr.it
}

\begin{abstract}
ICESat-2(Ice, Cloud, and land Elevation Satellite2), slated for launch in 2017 , will continue the important observations of ice-sheet elevation change, sea-ice freeboard, and vegetation canopy height begun by ICESat in 2003. Among the other potential applications, ICESat-2 could provide some information about atmospheric aerosol over Polar Regions thanks to the lidar instrument. In this context, it is essential to demonstrate the ICESat-2 capability of providing vertical profiles of the aerosol backscatter coefficient and to define its potentialities and limits. First results of this investigation are reported and will be presented at the conference.
\end{abstract}

\section{INTRODUCTION}

Polar Regions are fragile ecosystems strongly affecting the global climate conditions. On the other hand, they are also affected by pollution coming from close regions. Because of the severe conditions in those remote regions, few measurement sites and instruments are available there. For what concerns the atmospheric aerosols, measurements from satellite are limited because passive sensors retrievals are extremely complex for several aspects: underneath bright surfaces (ice cover), expected low aerosol load and low sun angle conditions. Lidar measurements overcome all these problems. Vertical profiles of aerosol optical properties over Polar Regions are provided by CALIOP lidar since June 2006 (16-day repetition cycle). Potential ICESat-2 data could improve the temporal and spatial coverage of aerosol data on Polar Regions. In addition, the availability of aerosol optical properties vertical profiles over Polar Regions from ICESat-2 and CALIOP (and then EarthCARE, the Earth Clouds, Aerosols and Radiation Explorer) would provide a long-term data record of aerosol content over Polar Regions for air quality, climate change and climatological applications. In particular, the aerosol impact on radiation forcing and ice cover could be investigating thanks to the ICESat-2 primary products, i.e. the ice sheet heights. However, the real feasibility of aerosol study through ICESat-2 backscatter signals has to be investigated.

Three main critical issues were identified for the ICESat-2 atmospheric aerosol investigation:
a. low signal-to-noise ratio
b. laser pulses aliasing
c. needs of lidar ratio assumptions

Points a-b are strictly related to the fact that ICESat-2 lidar was designed (and optimized) for topography purposes and their effects on atmospheric aerosol measurements capability have to be investigated into details. Point $\mathrm{c}$ is instead common for all elastic backscatter lidars as for example CALIPSO is. In this case, methods and implications are well known, but limiting our interest to Polar Regions lidar ratio assumptions could be optimized.

Within ICESat-2 Early Adopters program, the authors investigated these critical aspects to demonstrate the utility of ICESat-2 data for atmospheric aerosol studies.

\section{METHODOLOGY}

This feasibility study is not starting from scratch. We built on the "giants" shoulders, taking advantage from the knowledge and measurements collected by 3 reference observational platforms: AERONET (Aerosol Robotic NETwork), the ground based sunphotometer network [1], CALIPSO the first atmospheric lidar from satellite [2], and EARLINET (European Aerosol Research Lidar Network), the first lidar network for aerosol study on continental scale [3]. 
In particular, CALIPSO data could be used for simulating the ICESat-2 observations. On the other hand, an estimation of the lidar ratio values at $532 \mathrm{~nm}$, to be used for the backscatter retrieval, can be obtained from AERONET data. Finally, the knowledge resulting from EARLINET about lidar ratio values and CALIPSO data usage are particularly valuable for this study.

Facing the problems reported above, firstly, we limited our study to nighttime situation, because probably during the daytime, due to $a$, thin clouds and aerosols will be detectable only after a large average time (i.e. at least 40,000 lidar pulses, corresponding to about $28 \mathrm{~km}$ horizontal resolution).

The most critical point in ICESat-2 measurements is that the very high repetition rate of the laser $(10 \mathrm{Khz})$ results in the overlap of atmospheric scattering coming from altitude ranges separated by $15 \mathrm{~km}$ : the atmospheric scattering recorded by the instrument at height $\mathrm{H}$ is the sum of the scattering at height $\mathrm{H}, \mathrm{H}+15, \mathrm{H}-15, \mathrm{H}+30, \mathrm{H}-30$, $\mathrm{H}+45, \mathrm{H}-45$ etc., where the numbers are in $\mathrm{km}$. This has two main consequences: the calibration is limited at altitudes below $15 \mathrm{~km}$ and there is ambiguity in aerosol/cloud height product.

To define the feasibility of using ICESat-2 lidar data for atmospheric aerosol study over Polar Regions, we define 4 main objectives:

1. perform a statistical analysis of layers on Polar regions above $15 \mathrm{~km}$;

2. develop a reliability scheme for solving pulse-aliasing issue;

3. test the reliability score on CALIOP data;

4. define $S$ values for backscatter retrieval starting from AERONET data

A statistical analysis of layers over Polar Regions was performed using 1-year of CALIPSO measurements on North (lat $>66.33^{\circ} \mathrm{N}$ ) and South regions (lat $>66.33^{\circ} \mathrm{S}$ ), collected for the period Jan-Dec 2012. Since ICESat-2 data will be limited in daytime conditions, only night time measurements were considered. In particular, Level 2 aerosol layer products were used. Monthly analysis of layer base and top, and layer and columnar AOD were performed.
On the base of the collected statistics, the probability to observe layers above $15 \mathrm{~km}$ for each polar region and month as a function of the layer thickness was evaluated.

Finally, this reliability scheme was tested on some cases as observed by CALIPSO in 2013.

For what concerns the lidar ratio values to be used into the backscatter retrieval, AERONET data collected in the Polar Regions were analysed for estimating the lidar ratio values at $532 \mathrm{~nm}$ to be used for the backscatter retrieval. Starting from AERONET sun-photometer data it is possible to estimate the lidar ratio $S$ as:

$$
\mathrm{S}=4 \pi /\left(\mathrm{SSA} \cdot \mathrm{p}\left(180^{\circ}\right)\right)
$$

where $p(180)$ is the phase function at $180^{\circ}$ and SSA the single scattering albedo [4]. Considering the low mean AOD (0.24 at 440nm) in Europe, we had to consider also AERONET Lev1.5 products in the estimation of $\mathrm{S}$ ratio, because all cases with $\operatorname{AOD}(440 \mathrm{~nm})<0.4$ have been masked in official Lev2.0 (quality assured) products. All available data collected in the North (lat $>66.33^{\circ} \mathrm{N}$ ) and South polar regions (lat $>66.33^{\circ} \mathrm{S}$ ) were considered.

\section{RESULTS}

The statistical analysis performed on CALIPOS data shows that layers above $15 \mathrm{~km}$ are observed only during Nov-Feb and May-Sept period for North and South Pole, respectively. Moreover, layers extending above $15 \mathrm{~km}$ are typically thicker than $1 \mathrm{~km}$ (see for example Figure 1). The layer thickness results to be a constraining parameter for the development of a reliability scheme to the Icesat-2 measurements.

The scheme was tested on first examples of simulated data. CALIPSO real observations for 2013 were used. The signal coming from 15-30 $\mathrm{km}$ altitude region was added to the $0-15 \mathrm{~km}$ one. Figure 2 and 3 show the real measurements and the corresponding ICESat-2 simulated data, respectively. Applying the reliability scheme to this dataset we found that the $0.8 \mathrm{~km}$ thick layer observed at the beginning of the time series around $2.5 \mathrm{~km}$ is correctly identified as true layer(probability of coming from above $15 \mathrm{~km}$ around $5 \%$ ). The tenuous but $8 \mathrm{~km}$ deep layer observed between $3-10 \mathrm{~km}$ is instead identified as 
affected by the above $15 \mathrm{~km}$ region (probability greater than 99\%). This is in agreement with the real observation: this layer corresponds to the layer between 17 and $25 \mathrm{~km}$ observed in the rightbottom of corner of figure 2 .

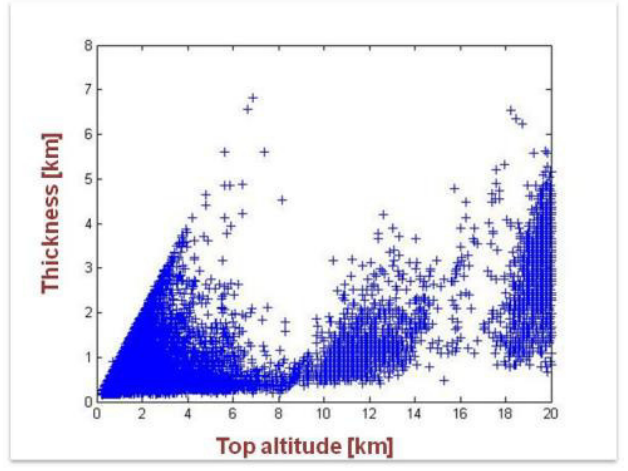

Figure 1: example of layer thickness vs top altitude values for data collected on January 2012, North Polar Region.

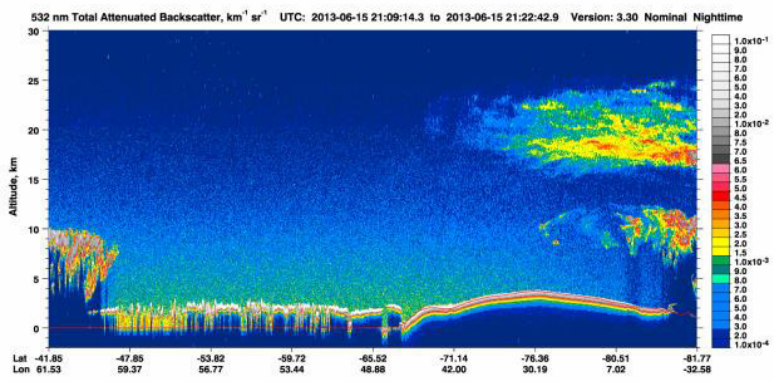

Figure 2: quick-look of CALIPSO attenuated backscatter at 532nm for 15 June 2013.

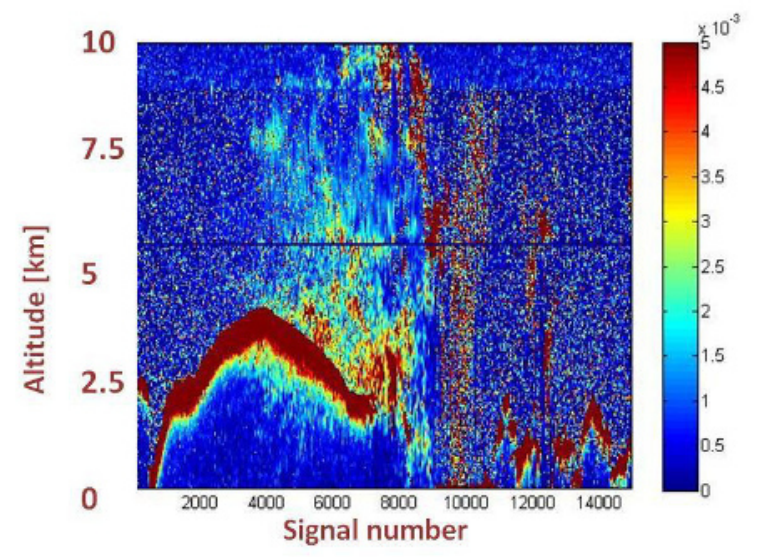

Figure 3: simulated ICESat-2 signals corresponding to North Polar Region section of figure 2.
The first examples of reliability scheme application indicate the feasibility of applying the developed reliability scheme to the Iceasat2 measurements.

For what concerns the polar lidar ratio values, first of all we found that unrealistic lidar ratio values were observed for low AOD values $(<0.025)$. WE found also that using median values instead of mean values, remove this aspect and gives results in agreement with the center of Gaussian fit for lidar ratio values distribution (R2>0.75) For the North Pole, data from 14 sites are available. No differences were observed for different geographical location of the sites. Grouping all North Pole lidar ratio data, we found data are Guassian distributed around a value of $58 \pm 16 \mathrm{sr}$. Only data from 2 stations are available for South Pole, which are Gaussian distributed around $67 \pm$ $2 \mathrm{sr}$.

These mean values are larger than what typically observed over Europe within EARLINET. However, it should be kept in mind that AERONET instrument cannot measure the backscatter coefficient but it is estimated by products $f$ inversions algorithms. A general tendency of AERONET overestimation of EARLINET directly measured lidar ratio values was observed comparing co-located data [5]. The estimated lidar ratio values for the Polar Regions have to be therefore compared with eventually available direct $\mathrm{S}$ measurements.

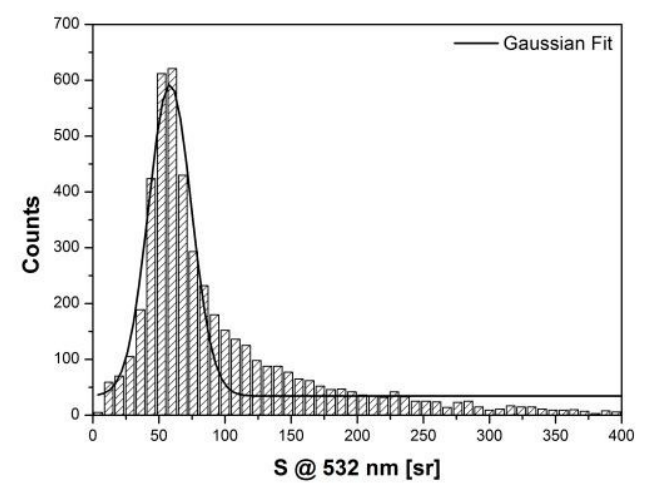

Figure 4: Counts distribution of lidar ratio values at 532nm as retrieved from AERONET inversion products (Level 15.5 data) for the North Polar Region. 


\section{CONCLUSIONS}

A preliminary feasibility study for using ICESat-2 lidar measurements for aerosol study is in progress. First results are promising, even if they should be better assessed. Moreover, the application of the developed methodology to ICESat-2 simulated data is needed for further improvements.

\section{ACKNOWLEDGEMENTS}

CALIPSO data were obtained from the NASA Langley Research Center Atmospheric Science Data Center. We thank the AERONET PI investigators and their staff for establishing and maintaining the sites used in this investigation. The authors would like to acknowledge Stephen P. Palm (Goddard Space Flight Center) for his comments and suggestions.

\section{REFERENCES}

[1] Holben, B.N., et al., (1998) Remote. Sens. Environ. 66, 1-16.

[2] Winker, D. M., et al., (2009) J. Atmos. Oceanic Technol., 26, 2310-2323.

[3] Pappalardo, G et al., (2014). Atmos. Meas. Tech., 7, 2389-2409.

[4] Welton, E.J., et al., (2002), Measurements of aerosol vertical profiles and optical properties during INDOEX 1999 using micropulse lidars, J. Geo. Res. 107 (19).

[5] Mona L., et al., (2009), A report on aerosol optical properties for both planetary boundary layer and free troposphere based on co-located AERONET and EARLINET data, GEOMON FP6 project deliverable

D3.1.2. 